\title{
MOVIMENTO DE PRODUÇÃO DOS NÚCLEOS DE EDUCAÇÃO PERMANENTE EM SAÚDE E DE HUMANIZAÇÃO NA REGIÃO DA CIES CARBONÍFERA
}

\author{
Diego Floriano de Souza \\ Acadêmico de Enfermagem, Universidade do Extremo Sul Catarinense, \\ diegoflorianodesouza@hotmail.com \\ Fabiane Ferraz \\ Doutora, Universidade do Extremo Sul Catarinense, \\ olaferraz@gmail.com \\ Valdemira Santina Dagostin \\ Mestra, Universidade do Extremo Sul Catarinense, \\ vsd@unesc.net \\ Ana Regina da Silva Losso \\ Mestra, Universidade do Extremo Sul Catarinense, \\ analosso@unesc.net \\ Ioná Viera Bez Birollo \\ Mestra, Universidade do extremo Sul Catarinense, \\ ionavieira71@hotmail.com \\ Luciane Bisognin Ceretta \\ Doutora, Universidade do Extremo Sul Catarinense, \\ luk@unesc.net \\ Cristiane Damiani Tomasi \\ Doutora, Universidade do Extremo Sul Catarinense, \\ cristiane_damiani@hotmail.com
}




\section{Ivanir Pra da Silva Thomé}

Mestra, Universidade do Extremo Sul Catarinense, ivanir_pdst@yahoo.com.br

\section{RESUMO}

A Educação Permanente em Saúde (EPS), enquanto política pública no Brasil, tem como pressupostos teóricos a aprendizagem significativa a partir das práticas cotidianas dos diferentes atores sociais envolvidos com os serviços de saúde, com o objetivo de provocar mudanças nos processos de trabalho. Essa política, atualmente, ainda é regida pela Portaria no $1.996 / 2007$, a qual estabelece o funcionamento, financiamento e transferência de recursos para EPS, bem como define que sua conduçáo ocorra pelas Comissóes Intergestores Regionais (CIR) e pelas Comissóes de Integração Ensino-Serviço (CIES). Está preconizado, teoricamente, que a CIES possua em sua composição gestores municipais e estaduais de saúde e educação, trabalhadores do Sistema Único de Saúde (SUS) e/ou entidades representativas, instituiçóes de ensino com cursos na área da saúde e movimentos sociais ligados à gestão das políticas públicas de saúde e do controle social no SUS. Entre suas atribuiçóes, estão propor, elaborar, monitorar e avaliar os projetos de EPS implantados, bem como fornecer informaçóes à CIR, a fim de orientar suas decisôes em relação ao Plano de Açáo Regional de Educação Permanente em Saúde (PAREPS) (BRASIL, 2009). A Política Nacional de Humanização (PNH) possui alguns pressupostos que dialogam diretamente com o preconizado pela EPS, pois seus princípios se operacionalizam colocando em análise os processos de trabalho, ou seja, a PNH propóe mudança dos modelos de atenção e de gestão, ainda fundamentados na racionalidade biomédica (SANTOS-FILHO, 2009). Frente a isso, vislumbra-se a formação de Núcleos Municipais de Educação Permanente em Saúde e Humanização (NEPSHU) como uma possibilidade de mobilizar a implementação de açóes que promovam a reflexão dos processos de trabalho e gestão, na realidade dos serviços, a partir da lógica de implicar as pessoas nos processos de mudança dos espaços de trabalho (FERRAZ, et al., 2012; SCHNEIDER, et al., s/d). O presente estudo tem como 
objetivo relatar os movimentos iniciados pelos membros da CIES Carbonífera, a fim de implantar e desenvolver Núcleos de Educação Permanente em Saúde e Humanização nos municípios da região carbonífera de Santa Catarina (SC). A CIES da região carbonífera se reúne na última terça-feira de cada mês, na estrutura física da 21 a Secretaria de Desenvolvimento Regional de SC. É uma organização dinâmica que, atualmente, está composta por 36 membros, abrangendo os segmentos de serviço, de ensino, de gestão e de controle social, com representantes de 12 municípios, que participam das reunióes para levantar e discutir açóes, financiamentos, investimentos e estratégias para implementar movimentos de EPS na regiáo. Entre os movimentos discutidos e organizados no ano de 2015, esteve a criação de grupos de trabalho que se responsabilizaram pela articulação, sensibilização e implantação de NEPSHUs nos municípios da regiáo. O processo foi desencadeado a partir da realizaçáo de um seminário ocorrido em agosto de 2015, promovido pela CIES, com recursos da Política de EPS e apoio da CIR e de instituição de ensino superior parceira. Nesse seminário, estavam presentes representantes dos 12 municípios da CIES Carbonífera e das instituiçóes de ensino. O seminário teve como tema a Política Nacional de Educação Permanente em Saúde e Humanização e contou com a participação dos responsáveis estaduais pela EPS e PNH, estudiosos das áreas de EPS e humanização e convidados que relataram seus processos de implantação de núcleos na região do Médio Vale do Itajaí (SC). A atividade teve como objetivo sensibilizar gestores e atores do controle social, a partir de um alinhamento teórico-metodológico, sobre a importância da EPS e humanização como estratégias de gestão para efetivação do SUS, expondo a possibilidade de criação de NEPSHUs para esse fim, além de sensibilizar os atores do controle social sobre a importância de participação na CIES Carbonífera. O seminário foi organizado em dois momentos: o primeiro foi no turno da manhá, estruturado em duas salas, sendo que, em uma sala, o controle social, por meio de roda de conversa, dialogou sobre os aspectos teórico-metodológicos expressos nas Políticas de EPS e Humanização e, ao final da manhã, sobre como essas políticas podem ser percebidas como uma estratégia de fortalecimento do controle social. $\mathrm{Na}$ outra sala, os gestores e trabalhadores municipais de saúde ouviram e dialogaram com estudiosos das áreas de EPS 
e Humanização, sobre os aspectos teórico-metodológicos das políticas e como essas são estruturadas em uma estratégia de gestáo. O segundo momento ocorreu à tarde, em que todos os participantes, em um auditório, acompanharam o relato de experiência de estruturação dos NEPSHUs na região do Médio Vale do Itajaí, onde participaram gestores, trabalhadores e membros do controle social que viveram essa experiência. Ainda à tarde, foi oportunizado que um município da região carbonífera, o qual já iniciou a implantação e operacionalização do seu NEPSHU, contasse sua vivência no processo. Após o referido seminário, os membros do Grupo de Trabalho (GT) da CIES Carbonífera vem organizando e implementando a segunda etapa do processo de implantação dos NEPSHU, que se estrutura a partir do estudo dos referenciais teórico-metodológicos das políticas na própria CIES, reservando um horário em toda reunião para estudo, bem como a divisão dos membros da CIES para realizar visitas aos municípios, a fim de mobilizar os atores da gestão, do trabalho e do controle social a estruturar os núcleos, sendo esse o atual momento que estamos vivendo. Em suma, busca-se com esta proposta de formar GT itinerantes, com facilitadores de EPS e humanização - membros da CIES -, que esses se desloquem até os municípios, a fim de possibilitar uma troca de saberes entre os atores deste processo, ocorrendo reflexão do e no processo de trabalho, para que a aprendizagem seja significativa e culmine na implantação e implementação de NEPSHU, mobilizando, assim, mudanças reais e significativas para o processo de pensar e de agir em saúde nos microespaços de trabalho e de gestão. Entre as limitações encontradas, há uma dificuldade de compreensão e de ação sobre a forma como a EPS é tratada pelos gestores e trabalhadores, pois, na maioria das vezes, limita-se a açóes de educação continuada no formato de cursos, que não ocorrem nos processos de trabalho, o que não coloca o cotidiano em análise. No entanto, acreditamos no potencial de mudança relacionado às articulaçóes desenvolvidas pela CIES Carbonífera, nos movimentos do trabalho em conjunto, na implicação de gestores, de trabalhadores, de instituiçóes formadoras e no controle social como o caminho para formular propostas responsáveis por mudanças nos processos de trabalho em saúde, no âmbito do SUS. 
Palavras-chave: Sistema Único de Saúde; Educação Permanente em Saúde; Promoção da Saúde; Humanização.

\section{REFERÊNCIAS}

BRASIL. Secretaria de Gestão do Trabalho e da Educação na Saúde. Política Nacional de Educaçáo Permanente em Saúde. Brasília: Ministério da Saúde, 2009.

FERRAZ, F. et al. Ações estruturantes interministeriais para reorientação da Atenção Básica em Saúde: convergência entre educação e humanização. O Mundo da Saúde, São Paulo, v.36, n.3, p.482-493, 2012.

SANTOS FILHO, S. B.; BARROS, M. E. B.; GOMES, R. S. A Política Nacional de Humanização como política que se faz no processo de trabalho em saúde. Interface: Comunicaçáo, Saúde e Educaçáo, São Paulo, v.13, n.1, p.603-613, 2009.

SCHNEIDER, A. C. et al. Implantação do Núcleo de Educaçáo Permanente em Saúde e Humanizaçáo. Brasília: Ministério da Saúde, s/d. 